\title{
Simulation study of solar air collector with offset strip fin absorber plate for drying agricultural products in a semi-arid climate
}

\author{
Abdelouahab Benseddik ${ }^{1,2,3^{*}}$, Ahmed Azzi ${ }^{2}$, Rachid Khanniche ${ }^{1}$, Abdul K. Allaf ${ }^{3}$ \\ ${ }^{1}$ Unité de Recherche Appliquée en Energies Renouvelables, URAER, Centre de Développement des Energies Renouvelables, \\ CDER, 47133, Ghardaïa, Algeria \\ ${ }^{2}$ Unité de Recherche Matériaux et Energies Renouvelables (URMER), Faculté des Sciences, Université de Tlemcen, BP 119, \\ Tlemcen 13000, Algeria \\ ${ }^{3}$ University of La Rochelle, Laboratory of Engineering Science for Environment (LaSIE) UMR 7356 CNRS - La Rochelle, \\ France
}

Corresponding Author Email: a_benseddik2008@yahoo.fr

https://doi.org/10.18280/ijht.360219

Received: 18 September 2017

Accepted: 14 May 2018

\section{Keywords:}

solar drying, mathematical modeling, numerical simulation, parametric investigation, optimal air mass flow rate

\begin{abstract}
In this current contribution, a parametric investigation of air flow rate at the inlets of solar air collector was carried out. Through a developed Matlab code effort was made to show the effect of the air flow rate on solar collector outlet temperature. From the simulation results a database of outlet temperature and corresponding flow rate variation with time was created. Then, isotherm contours were deduced and plotted. For drying temperature kept constant at a given value regardless the meteorological conditions fluctuation, the flow rate variation with time was fitted by smoothing spline function. The simulation study was done for three different meteorological scenarios: Clear sky day, partly cloudy day and cloudy day. It has been found also that drying with variable flow rate at optimum temperature equal to $50 \pm 1^{\circ} \mathrm{C}$ the amount of air that was aspired at the inlet was $1207.8 \mathrm{~kg}$. By contrast, drying with constant flow rate a total $625.5 \mathrm{~kg}$ of air was aspired and it might result in fluctuation in drying temperature which affects the dried product quality. Thus variable flow rate allows a gain ratio in the aspired air amount of $93 \%$ and better product quality. This is valid for clear sky day. In case of partly and cloudy day, flow rate gain ratio was $104 \%$ and $78 \%$ respectively.
\end{abstract}

\section{INTRODUCTION}

Solar energy constitutes an enormous potential for solar drying process, mostly, for agricultural products drying applications. Solar energy is the option of first choice in heating and drying processes because of the used air which is readily warm without a need of preheating facility. Most fruits and vegetables comprise nearly eighty percent of water and are highly vulnerable to temperature and thus are quickly perishables. In developing countries wastes rate of fruits and vegetables lay between $30-40 \%$ of total production [1]. Thus, the need to reduce post-harvest waste is a major concern in these countries. Nonetheless, post-harvest wastes can significantly be reduced to acceptable levels by using adequate and accurate drying systems in rural areas. Knowing that for small scale production, solar drying technologies when used for drying fruits and vegetables features: (i) are one such lowcost technology requiring no electricity, (ii) no skilled manpower and capital are needed, (iii) provide employment in rural areas [2]. Given that the solar air collector is the most important element of solar drying system, it follows that a proper design of solar air collector would enhance noticeably performances of the overall drying system.

Most of solar drying systems are equipped with flat solar air collector. The major drawback of such arrangement resides in low thermal exchanges capacity with air flowing through. Nonetheless, the rate of thermal exchange can be improved by increasing the area of thermal exchange and turbulence [3].
Several techniques were proposed and implemented to improve heat transfer rate between absorber and mobile air. Corrugated absorber, [1, 5-7] Recyclable Aluminum cans (RAC) absorber [8], absorber fitted with rows of fins [9] and various artificial roughness geometries [10-13]. Yeh and Lin [4] studied the effect of placing parallels obstacles on solar air collector efficiency. Nayak and Singh [14-15] investigated a jet plate solar air heater designed with continuous longitudinal fins underneath the absorber plate. Abene et al. [16] examined several types of longitudinal barriers in the passage of air flow. Singh [17] studied the effect of longitudinal fins on obtained power, particularly, the influence the gap between adjacent fins and he has proved that by reducing this gap the efficacy is remarkably increased. Goel and Singh [18] examined the solar air heater with longitudinal fins attached under the absorber. Giovanni [19] has studied experimentally inserted ducts, rendered rough with different vein configurations. These tremendous design modifications gave better thermal performances when compared to flat solar air collector. Generally, it has been demonstrated in literature that solar air collectors with corrugated absorber or fitted with fins have a noticeably higher efficacy when compared to solar air collector with horizontal parallel plates without a net drop in pressure [20-22].

In conclusion, the insertion of offset strip fin in air flow passage between absorber and solar air collector has significantly increased thermal exchange surface and hence obtaining a turbulent flow favoring advection thermal 
exchange between air and absorber. However, if the temperature of the drying is too high, nutritive value of the dried product will be deteriorated, and the product develops an over crispy like color where the inside of product remains relatively humid. This may enhance a global degradation of product on large scale. For example, Lim et al. [23] as cited in [24] reported that most fruits contain various antioxidants elements beneficial to human health by reducing degenerative diseases probability such as cancer, arthritis, arteriosclerosis, heart diseases, inflammation, brain dysfunction and ageing process. This claim is again proved by the work of [25-30] who stated that both vitamin $\mathrm{C}$ and total phenolics decreased with the increase of air-drying temperature.

The influence of flow rate on air temperature at outlet of the solar air collector is well reported in literature, [31-34] however, the study of its instantaneous influence over the entire drying day on air temperature has never been dealt with in details [35-36].

In the current contribution a polynomial function relating air flow rate as a function of time was elaborated based on the result of simulation. This function allows the variation of air flow rate versus time such that the desired drying temperature is kept constant over the entire drying process regardless of the variation of meteorological conditions including solar irradiance level.

In this current contribution, we considered meteorological data taken from the site i.e. Ghardaïa (semi-arid climate). These data comprise the fluctuation in meteorological conditions including solar radiation variations and ambient temperature during different sky types. This study leads to the analysis of different sky types that are used for planning and analyzing solar energy systems [37]. These are: clear sky, partly cloudy sky, and cloudy sky. In the end, we elaborated a code enabling determination of instantaneous temperature at the outlet of the solar air collector while varying the flow rate at the inlet. Two typical summer days are chosen; the first typical day is characterized by a clear sky and the second one is characterized by a cloudy sky. Besides that, a typical partly cloudy winter day is also considered.

\section{MATERIALS AND METHODS}

\subsection{Experimental measurements}

Global and diffuse solar radiation on horizontal plan is measured using a radiometric station located in our research facility (URAER). It comprises a pyranometer of type EKO. Temperature is measured using hygrometric probe Techoel sonde thermo-igrometriche with calibration accuracy ranging between $\pm 1.5 \%$, its resolution to ambient temperature is about $0.1\left({ }^{\circ} \mathrm{C} / \mathrm{mV}\right)$ and its dynamic range lies between 0 and $100 \% H R,-40$ à $+60^{\circ} \mathrm{C}$. All transducer are connected to a data-acquisition unit of type CAMPBELL SCIENTIFIC CR10x with programmed scan step time in the range of 5 minutes.

\subsection{Mathematical modeling}

\subsubsection{Mathematical modeling of solar radiation}

Design, simulation and evaluation of solar system performances require prior assessment of solar resources falling on horizontal and tilted surfaces alike. In this contribution particular interest is made to solar radiation falling on inclined plane. The studied solar air collector is located in semi-arid area (Ghardaïa: $32.4^{\circ} \mathrm{N}, 3.8^{\circ} \mathrm{E}$ ), $468 \mathrm{~m}$. URAER radiometric station is able to collect the following data: (i) Global solar irradiance received on horizontal surface $G_{h}$; (ii) Diffuse solar irradiance $D_{h}$ fallen on horizontal surface. The beam solar irradiance is found from:

$S_{h}=G_{h}-D_{h}$

The global solar irradiance $G_{I}$ is calculated as function of irradiance recorded on horizontal plan. It suffices to replace the given value by those recorded by Pyranometer in equation reported in, [41] as follows :

$G_{I}=R_{b} S_{h}+R_{d} D_{h}+R_{r} \rho G_{h}$

where: $R_{b}$ is the ratio between beam irradiance falling on tilted surface to that falling on horizontal, $R_{d c}$ is the ratio between diffuse irradiance on tilted surface to that of diffuse irradiance falling on horizontal surface, the $R_{r} \rho$ represents solar irradiance falling on tilted surface that is reflected by the ground, $\rho$ is ground albedo coefficient.

The term $R_{b}$ is calculated as follows:

$R_{b}=\frac{S_{n} \cos \theta_{\beta}}{S_{n} \cos \theta}$

where: $S_{n}$ is beam normal irradiance, whereas $\theta$ and $\theta_{\beta}$ are angles of incidence of solar irradiance respectively on tilted and horizontal surfaces. The incidence angle is given as follows [32]:

$\cos \theta_{\beta}=\sin \delta \sin \phi \cos \beta-\sin \delta \cos \phi \sin \beta \cos \gamma+$ $\cos \delta \cos \phi \cos \beta \cos \omega+\cos \delta \sin \phi \sin \beta \cos \gamma \cos \omega+$ $\cos \delta \sin \beta \sin \gamma \sin \omega$

where $\delta$ is solar declination angle, $\phi$ is latitude angle, $\beta$ tilt angle, $\gamma$ surface azimuth angle $\omega$ solar hour angle. These parameters are calculated as below [41]:

$\delta=23,45 \cdot \sin [0,98 .(j+284)]$

$\omega=15 .(T S-12)$

$T S=(L C T-L C)+\frac{E T}{60}+C$

where: $T S$ is the solar time, $L C T$ is the local clock time, $L C$ is the longitude correction, ET is the equation of time given by:

$E T=\left[0,0002-0,4797 \cdot \cos \left(\omega^{\prime} j\right)+3,2265 \cdot \cos \left(2 \cdot \omega^{\prime} j\right)+\right.$ $0.0903 \cos \left(3 . \omega^{\prime} j\right)+7,3509 . \sin \left(\omega^{\prime} j\right)+$

$\left.9,3912 \cdot \sin \left(2 . \omega^{\prime} j\right)+0.3361 \cdot \sin \left(3 . \omega^{\prime} j\right)\right]$

where: $C$ is legal time correction; for Algeria $C=-1$ thus: in case of Algeria, Eq. (7) becomes as follows:

$T S=(L C T-L C)+\frac{E T}{60}-1$

The term $\cos \theta$ expression may be obtained from Eq. (4), when tilt angle $\beta$ is set equal to zero. The incidence angle is calculated as an average value in time interval of each hour.

Optimum surface azimuth angle $\gamma=0^{\circ}$ and hence $R_{b}$ is written as follows: 
$R_{b}=\frac{\cos (\phi-\beta) \cos \delta \cos \omega+\sin (\phi-\beta) \sin \delta}{\cos \emptyset \cos \delta \cos \omega+\sin \phi \sin \delta}$

The ground reflected irradiance is considered as if it were isotropic such way that the term $R_{r}$ is calculated as [41]:

$R_{r} \cong \frac{(1-\cos \beta)}{2}$

The equation used for calculating of diffuse irradiance transposition irradiance factor $R_{d}$, with isotropic model is given by Liu and Jordan (1963) as [41]:

$R_{d} \cong \frac{(1+\cos \beta)}{2}$

\subsubsection{Mathematical modelling of solar air collectors}

The process of solar thermal energy that we attempt to investigate is solar drier without energy storage system (Figures 1 and 2). Hence, solar air collector is considered with simple path between absorber and aluminum plat placed over solar air collector to obtain moderate, yet, sufficient and appropriate temperatures for solar drying process. The purpose behind inflexion of fins for mobile air passage is to enhance thermal performances of solar air collector. For the present study, the dimensionless parameters were chosen as: the fin pitch $(s=0.016 \mathrm{~m})$, the fin length $(l=0.1 \mathrm{~m})$, the fin thickness $(t$ $=0.004)$ and the fin height $(h=0.021 \mathrm{~m})$. The overall dimension of the solar air collector is chosen to be $\left(L_{c}=1.6 \mathrm{~m}\right)$ in length and $\left(l_{c}=0.8 \mathrm{~m}\right)$ in width.

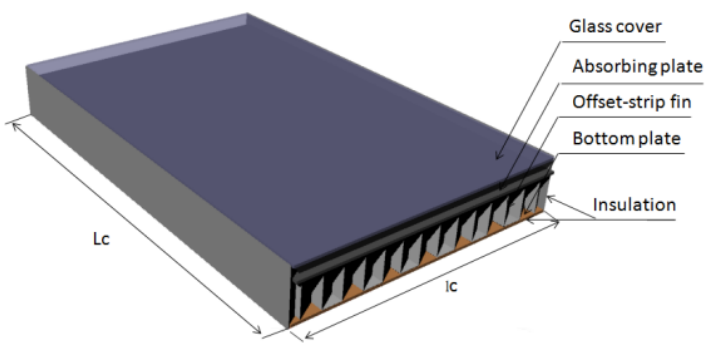

Figure 1. Schematic view of the solar air collector with offset strip fin attached

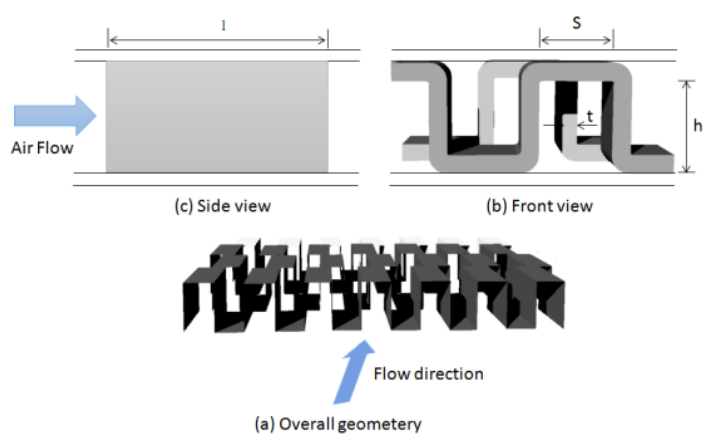

Figure 2. Schematic diagram of the strip fin attached

The selected method of solar air collector modeling is the one implemented by Hottel, Whillier and Bliss [41]. It is based upon the assumption that the permanent regime is established and that solar air collector elements are at average constant temperatures, thermal inertial effect are neglected.

Our approach is also based on these assumptions to model the solar air collector because temperature variation at solar collector input is small and the performances to be determined are permanents.

Heat equation for air flowing flow is written as:

$\rho_{f} C_{p}\left(\frac{\partial T_{f}}{\partial t}+V_{f} \overrightarrow{g r a d} T_{f}\right)=\operatorname{div}(\vec{q})+\sigma_{T}$

In steady state by neglecting the conduction in air flowing flow it becomes:

$\rho_{f} C_{p} V_{f} \overrightarrow{\operatorname{grad}} T_{f}=\sigma_{T}$

If the air flowing flow is along $x$ ordinate, this equation becomes:

$\rho_{f} C_{p} V_{f} \frac{d T_{f}}{d x}=\sigma_{T}$

or:

$\sigma_{T}=\frac{P u}{e}$

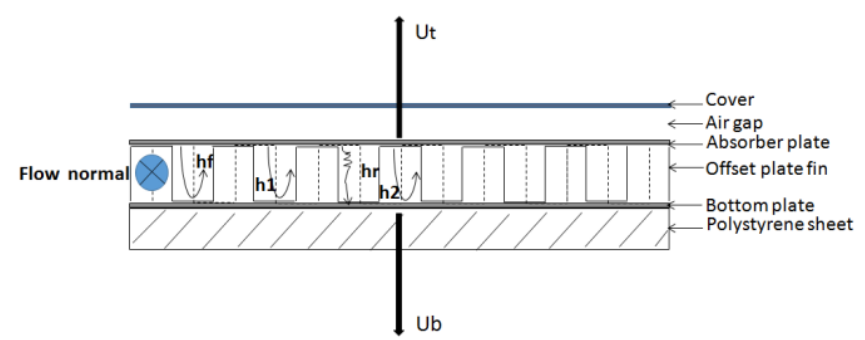

Figure 3. Schematic representation of heat transfer in the solar collector

While introducing the solar air collector, the overall loss coefficient between the absorber and the ambient air $U_{L}$, the useful power gain provided by the solar air collector is given by Eq. (17) [41]:

$P u=A_{c} F^{\prime}\left(\left(\tau_{v} \alpha_{n}\right) G_{I}-U_{L}\left(T_{f}-T_{a}\right)\right)$

By introduction the specific mass flow $\dot{m}$, the heat equation in air flowing flow can be rewritten as:

$\dot{m} C_{p} \frac{\partial T_{f}}{\partial x}=l_{C} \cdot F^{\prime}\left(\left(\tau_{v} \alpha_{n}\right) G_{I}-U_{L}\left(T_{f}-T_{a}\right)\right)$

The first order differential equation, Eq. (18) is subjected to the following boundary condition:

$T_{f}(x=0)=T_{f e}$

If we assume that $F^{\prime}$ and $U_{L}$ are independent of position $x$, then the solution of $\mathrm{Eq}(18)$ is:

$\frac{T_{f}-T_{a}-\left(\tau_{v} \alpha_{n}\right) G_{I} / U_{L}}{T_{f e}-T_{a}-\left(\tau_{v} \alpha_{n}\right) G_{I} / U_{L}}=\exp \left(-\frac{U_{L} F^{\prime} l_{C} x}{\dot{m} C_{p}}\right)$

If the solar air collector has a length $L$ in the flow direction, then the outlet air temperature $T_{f S}$ is foundby substituting $L$ for $x$ in $\mathrm{Eq}(20)$, noting that $l_{C} L_{c}$ is the solar air collector area $A_{c}$ : 
$\frac{T_{f s}-T_{a}-\left(\tau_{v} \alpha_{n}\right) G_{I} / U_{L}}{T_{f e}-T_{a}-\left(\tau_{v} \alpha_{n}\right) G_{I} / U_{L}}=\exp \left(-\frac{U_{L} F^{\prime} A_{c}}{\dot{m} C_{p}}\right)$

The solar air collector efficiency factor $F^{\prime}$ and solar air collector overall loss coefficient $U_{L}$ for the offset-strip fin shown in Figure 3 are obtained from the energy balances on the absorber plate, the fluid, and the back plate as in (Figure 3) [42].

$F^{\prime}=\frac{h_{r} h_{2} \eta_{s}+h_{r} h_{1}+U_{b} h_{1}+h_{1} h_{2} \eta_{s}}{\left(U_{t}+h_{1}+h_{r}\right)\left(U_{b}+h_{2} \eta_{s}+h_{r}\right)-h_{r}^{2}}$

$U_{L}=\frac{\left(U_{b}+U_{t}\right)\left(h_{r} h_{2} \eta_{s}+h_{r} h_{1}+h_{1} h_{2} \eta_{s}\right)+U_{b} U_{t}\left(h_{1}+h_{2} \eta_{s}\right)}{h_{r} h_{2} \eta_{s}+h_{r} h_{1}+U_{b} h_{1}+h_{1} h_{2} \eta_{s}}$

\subsection{Empirical correlation of the offset strip fins}

This surface has one of the highest heat transfer performances relative to the friction factor. Extensive analytical, numerical and experimental investigations have been conducted over the last 50 years [43]. For the conventional air heater (without fin in the air flow pass), the heat transfer coefficients in the equations could be determined by empirical equations [44-48]. While, adding offset strip fins on the absorber plate would change both the heat transfer coefficient in the air flow pass, which differs from the conventional heater model, is discussed in detail as follows. Many different correlations for heat transfer in offset strip fin (Figure 2) heat exchangers have been reported in literature. The Colburn factor $j$, defined in Eq. (24), by Manglik and Bergles [41] for rectangular offset strip fin cores are given as (Figure 2):

$j=0.6522 R e^{-0.5403} \alpha^{-0.1541} \delta^{0.1499} \gamma^{-0.0678}[1+$

$\left.5.26910^{-5} \alpha^{0.504} \delta^{0.456} \gamma^{-1.055}\right]^{0.1}$

where the dimensionless parameters $\alpha=s / h, \delta=$ $t / l$ and $\gamma=t / s$ describe the offset strip fins geometry. This correlation predicts the experimental data of 18 test cores within $\pm 20 \%$ for $120<R e<10^{4}$ and for ratios $0.134<$ $\alpha<0.997,0.012<\delta<0.048$ and $0.041<\gamma<0.121$. Although all experimental data for these correlations are obtained for air, the $j$ factor takes into consideration minor variations in the Prandtl number, and the correlations above should be valid for $0.5<\operatorname{Pr}<15$.

The Colburn factor is related to Stanton number and Prandtl number as [43]:

$j=S t \cdot \operatorname{Pr}^{1 / 3}=\frac{N_{u} P r^{-1 / 3}}{R e}$

The convective heat transfer is normally derived from the following equation, that:

$h_{1}=h_{2}=h_{f}=\frac{N_{u} \lambda_{f}}{D_{H}}$

The Reynolds Number $R e$ is calculated by [43]:

$R e=V_{f} \frac{D_{H}}{v_{f}}$

The average velocity in the across section $V_{f}$ is expressed as:
$V_{f}=\frac{\dot{m}}{\rho_{f} A_{d}}$ [49]:

The cross sectional area $A_{d}$ in the air flow pass is defined as

$A_{d}=l_{c}(h+t)-\frac{l_{c} t}{s+t}(s+h+t)$

And, the hydraulic diameter $D_{H}$ is then given by [43]:

$D_{H}=\frac{4 s h l}{2(s l+h l+t h)+t s}$

Also $\eta_{\mathrm{s}}$ in equations (22) and (23), is defined as [50]:

$\eta_{s}=1-\frac{A_{f}}{A_{c}}\left(1-\eta_{f}\right)$

where:

$A_{f}=2 h l+2 h \delta+s \delta$

$\eta_{f}=\frac{\tanh (m l)}{m l}$

where:

$m l=\left[\frac{2 h}{k_{f} \delta}\left(1+\frac{\delta}{l}\right)\right]^{1 / 2}\left(\frac{D}{2}-\delta\right)$

\subsection{Empirical correlation of the offset strip fins}

The radiation heat transfer coefficient between the inner wall of the absorber plate and the aluminum plate, where the temperatures $T_{n}$ and $T_{2}$, is calculated from [51]:

$h_{r}=\frac{\sigma\left(T_{n}+T_{2}\right)\left(T_{n}^{2}+T_{2}^{2}\right)}{\left(\frac{1}{\varepsilon_{1}}+\frac{1}{\varepsilon_{2}}-1\right)}$

An empirical equation for $U_{t}$ that is useful for both hand and computer calculations for the loss coefficient through the top of the solar air collector were developed by Klein (1975). He followed the same procedure as Hottel and Woertz (1942) and Klein (1975) [41]:

$U_{t}=\left\{\frac{N}{C / T_{n}\left(\frac{\left(T_{n}-T_{a}\right)}{(N+f)}\right)^{e}}+\frac{1}{h_{v v}}\right\}^{-1}+$
$\frac{\sigma\left(T_{n}+T_{a}\right)\left(T_{n}^{2}+T_{a}^{2}\right)}{\left(\varepsilon_{n}+0.00591 N h_{w}\right)^{-1}+\frac{\left(2 N+f-1+0.133 \varepsilon_{n}\right)}{\varepsilon_{v}}-N}$

This relationship fits the graphs for $U_{t}$ for mean plate temperature between ambient and $200^{\circ} \mathrm{C}$ to within $\pm 0.3 \mathrm{w} / \mathrm{m}^{2 \circ} \mathrm{C}$. In this equation $T_{a}$ and $T_{n}$ are in [K]. where $N$ is the number of glass covers $N=2, f=$ $\left(1+0.089 h_{v v}-0.1166 h_{w} \varepsilon_{n}\right)(1+0.07866 N) \quad, \quad C=$ $520\left(1-0.000051 \beta^{2}\right)$ for $0^{\circ}<\beta<70^{\circ}$. For $70^{\circ}<\beta<$ $90^{\circ}$, use $\beta=70^{\circ} ; e=0.430\left(1-100 / T_{n}\right) . h_{w}$ is defined as [21]: $h_{w}=5.67+3.86 V_{w}$

The loss coefficient through the bottom of the solar air collector:

$U_{b}=\left[\frac{e_{i s}}{\lambda_{i s}}+\frac{e_{b}}{\lambda_{b}}+\frac{1}{h_{w}}\right]^{-1}$ 


\subsection{Estimating from simulation results}

The determination of the function that describes the variation of air flow rate in function of time under site common solar irradiance scenarios is essential. This is achieved by simulating the system using an elaborated Matlab code. The outcome of this code are values of flow rate which give a constant drying temperature equal to $50 \pm 1{ }^{\circ} \mathrm{C}$ during the entire drying process regardless of the meteorological conditions. The obtained data set are fitted using smoothing spline method. Simply put, smoothing spline method allows determination of fitting curve by using an adequate number of piecewise cubical polynomials that approximate smoothly the data points [52-54]. In fact the smoothing spline can be computerised by storing the polynomials coefficients in an array.

\subsection{Smoothing Spline interpolation method}

For the daily values of air flow rate necessary to achieve an optimum temperature $\left(t_{i}, \dot{m}_{\text {opt }}\right), i=1, \ldots, n$, the smooth function $f(t)$ is the solution of the minimization problem.

$\frac{1}{n} \sum_{i=1}^{n}\left(\dot{m}_{o p t_{i}}-f\left(t_{i}\right)\right)^{2}+P \int_{t_{1}}^{t_{n}}\left(f^{(k)}\right)^{2} d u$

where $P$ is the smoothing parameter and $f^{(k)}$ is the $k$ th dirivative of $f$. If $k=2$, then $f$ is a cubic smoothing spline. The first term in Eq. (38) is the residual sum of squares, an indicator of the goodness-of-fit of the spline curve to the data. In other words, it measures the degree of fidelity of the smoothing spline function to the data. The second term measures the roughness of the resulting smoothing spline curve. The roughness of a function can be characterized by its curvature. The smoothing parameter $P$ plays an important role. It weighs two aspects: smoothness and fit. Large values of give a smoother curve, while small values of result in a closer fit.

\subsection{Integrating smoothing spline curve}

In smoothing spline curve, the function is only known at a finite set of points, say $\left(t_{i}, \dot{m}_{o p t_{i}}\right), i=1, \ldots, n$. Assume the $t$ 's are sorted in increasing order, with $a=t_{1}<t_{2}<\cdots<$ $t_{n}=b$

For approximate the integral $\int_{a}^{b} \dot{m}_{o p t}(t) d t$, the most obvious approach is to integrate the piecewise linear function that interpolates the data. This leads to the composite trapezoid rule

$T=\sum_{i=1}^{n-1} h_{i} \frac{\dot{m}_{o p t_{i+1}}+\dot{m}_{o p t_{i}}}{2}$

where $h_{i}=t_{i+1}-t_{1}$.

\subsection{Error analysis}

Fitting quality of the smoothing spline interpolation used on the data obtained by mathematical model was evaluated by means of statistical tests: The coefficient of determination $\left(\mathrm{R}^{2}\right)$, sum of square error ( $\left.S S E\right)$, and root mean square error (RMSE). These parameters can be calculated as follows [55, 56]:
$R^{2}=1-\frac{\sum_{i=1}^{N}\left(\dot{m}_{o p t_{\text {data }, i}}-\dot{m}_{o p t_{\text {pre }, i}}\right)^{2}}{\sum_{i=1}^{N}\left(\overline{\dot{m}}_{\text {opt }}{ }_{\text {data }}-\dot{m}_{\text {opt }}{ }_{\text {data }, i}\right)^{2}}$

$S S E=\frac{1}{N} \sum_{i=1}^{N}\left(\dot{m}_{o p t_{\text {data }, i}}-\dot{m}_{\text {opt }}{ }_{\text {pré, } i}\right)^{2}$

$R M S E=\sqrt{\frac{\sum_{i=1}^{N}\left(\dot{m}_{o p t}{ }_{\text {data }, i}-\dot{m}_{o p t_{p r e ́}, i}\right)^{2}}{N}}$

With:

$\overline{\dot{m}_{\text {opt }} \text { data }}=\frac{\sum_{i=1}^{N} \dot{m}_{o p t_{\text {data }, i}}}{N}$

where $\dot{m}_{\text {opt }}$ data,i is the data of air flow rate obtained by calculation using models of solar air collector, $\dot{m}_{o p t_{\text {pré }, i}}$ is predicted values of air flow rate necessary to achieve an optimum temperature obtained by calculating from the model. $N$ is the number of observations.

\section{RESULTS AND DISCUSSION}
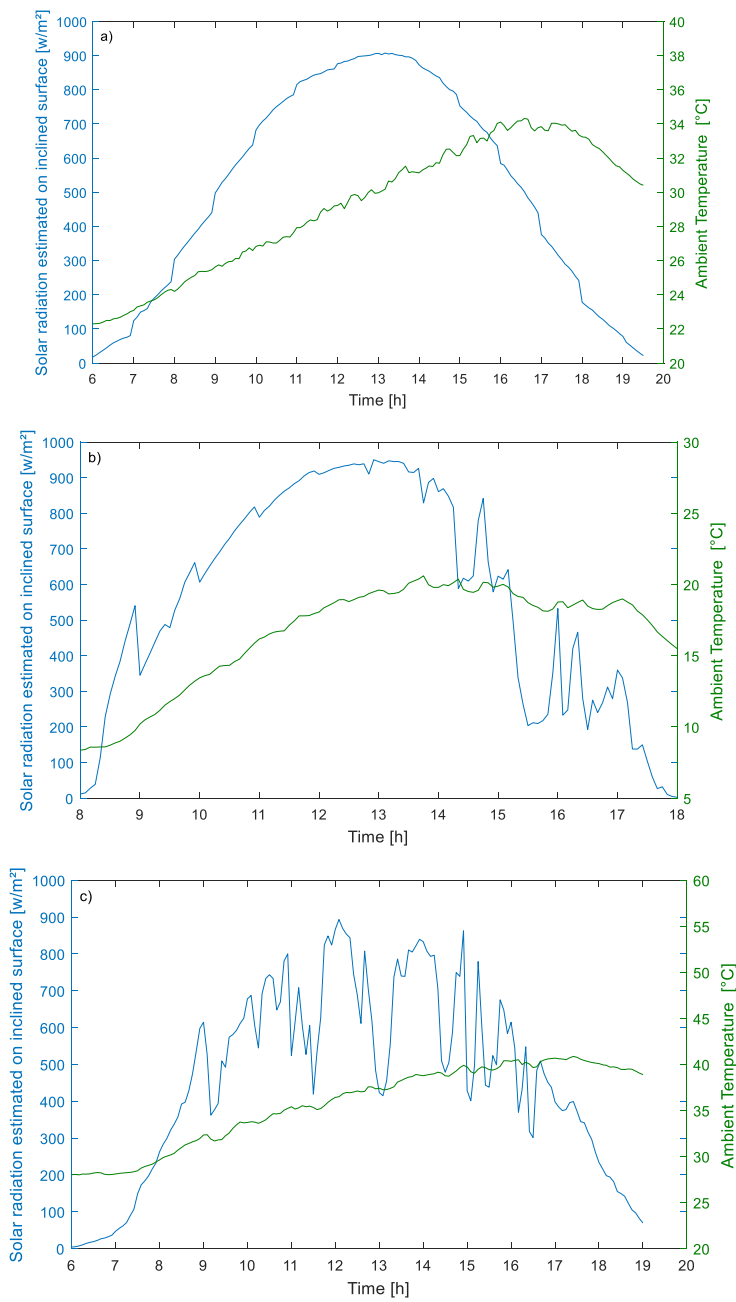

Figure 4. Variation of solar flux and ambient temperature: On: a) 06/11/2008 (Clear Sky), b) 01/14/2008 (Partly Cloudy sky) and c) 07/15/2008(Cloudy sky) 
The global solar irradiance on tilted surface $G_{I}$ as Shown in (Figures 4a), 4b) and 4c)) is calculated as a function of incident irradiance on horizontal surface using Liu and Jordan model described above. In this work, different sky conditions are considered: (i) a clear sky day (Figure 4a)), (ii) a partly cloudy day (Figure 4b)) and (iii) a cloudy day (Figure 4c)). The choice of fully midsummer cloudy day and early summer clear sky day is made to represent respectively the worst unusual and typical radiation budget scenarios and they correspond to crop harvesting season. Thus this choice provides a solution to keep post harvest waste to minimum.

In case of the third choice (partly cloudy winter day), it is made to demonstrate the possibility of using solar drying at optimal temperature at low irradiance values. This may be exploited to dry greenhouses products and medicinal herbs.
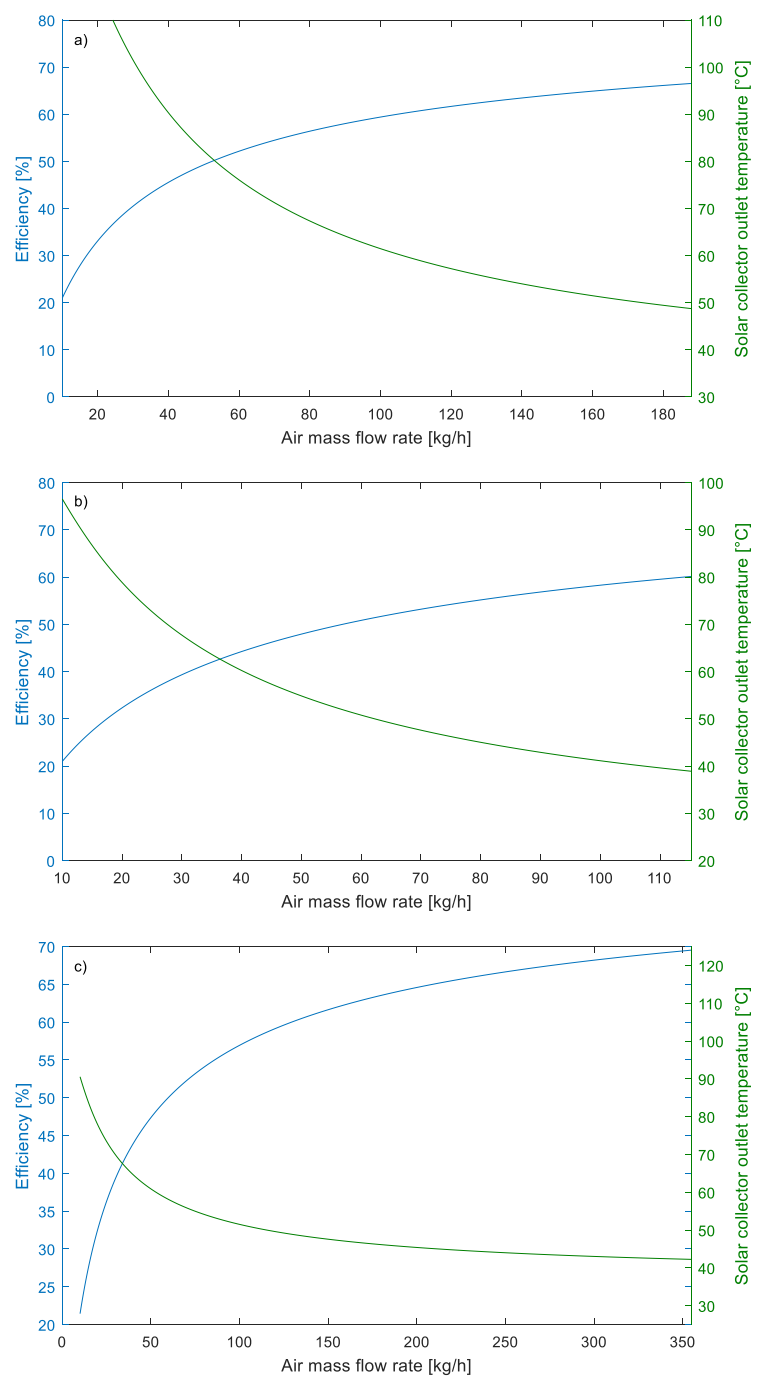

Figure 5. Efficiency and output temperature at solar noon: On: a) 06/11/2008 (Clear Sky), b) 01/14/2008 (Partly Cloudy sky) and c) 07/15/2008(Cloudy sky)

Figures 9a), 9b) and 9c) show that at a given time, the output temperature decreases in continuous manner with increase in flow rate and as the temperature of air decreases with increase flow rate, results in an increased efficiency. This may be explained by the fact that as the flow rate increases, the associated power is maintained constant as it was resulted from constant solar radiation source. In other way, as the amount of heated air increases the output temperature decreases. At solar noon, to maintain the prescribed drying temperature, the airflow is increased to about $188.1 \mathrm{~kg} / \mathrm{h}$ for clear day, $115.3 \mathrm{~kg} / \mathrm{h}$ for partly cloudy day and $355.1 \mathrm{~kg} / \mathrm{h}$ for cloudy day.

Figures 5a), 5b) and 5c) show the relationship between output temperature and efficiency in function of air flow rate. The former figure is typical of clear sky day whereas the latter figure is typical of cloudy day. The obtained results by $[3,16]$ show the same aspect. These results show the strong influence of the effect of air flow rate on solar air collector output temperature. In order to select an appropriate flow rate, we should consider both the efficiency and the prescribed output temperature. As the solar air collector thermal transient inertia is important, it is difficult to determine its efficiency using an experimental approach. Therefore, simulation option offers an adequate means to overcome this difficulty.

The outlet solar air collector temperature is an essential parameter for solar drying application. Taking into account this fact during our work, efforts were made to show isotherm temperatures for large range of flow rate that may penetrate the solar collector under different irradiance scenarios. To be more specific, the first task of the simulation code is to keep the flow rate constant over the entire simulation time and then record the temperature at the outlets. This task is repeated for the entire range of the flow rate. This flow rate ranges between a minimum and maximum values determined by Reynolds number. These results are then used to plot the isotherm contours i.e. the flow rate variation in function of time to obtain a given temperature (Figures 6a), 6b) and 6c)).

We can clearly observe that during cloudy day the passage of clouds has an immediate effect on global solar radiation incident on the solar air collector as shown in (Figures 4a), 4b) and 4c)) where its effect on isothermal is also immediate.

In Figures 6a), 6b) and 6c), isotherm contours are subject to a number of fluctuations as a result of clouds passage and fluctuations in ambient temperature. To keep the outlet temperature constant the flow rate is increased in case of high level irradiance values. Conversely, at low level irradiance values to keep the temperatures constant the flow rate should be decreased.

The selection of drying temperature is critical as it has serious implications on final dried products quality. Choosing low temperature engenders micro organism growth, which alters the dried product quality. On the other hand, opting for high temperatures will also have deteriorating effects on the final dried products [57]. According to the found results the most suitable drying temperature lies between minimum and maximum drying temperature which are respectively 35 and $65{ }^{\circ} \mathrm{C}$ [58-60]. Based on the above it can be inferred that selection drying temperature around $50{ }^{\circ} \mathrm{C}$ is the best choice and in this work it is maintained at $50 \pm 1{ }^{\circ} \mathrm{C}$ regardless the fluctuation of meteorological conditions.

In addition to the selection of suitable drying temperature, the determination of the function that describes the variation of air flow rate in function of time is essential. From the above results a database of air flow rate in function of time and temperature is established. Thus, air flow rate in function of time is elaborated to keep the dryer temperature equal to the prescribed value through all the drying process. For instance, Figure 6a) demonstrates clearly the above stated claim in case of cloudy day, Figure 6b) for Partly Cloudy day and Figure 6c) for clear day for desired temperature of $50 \pm 1^{\circ} \mathrm{C}$. 

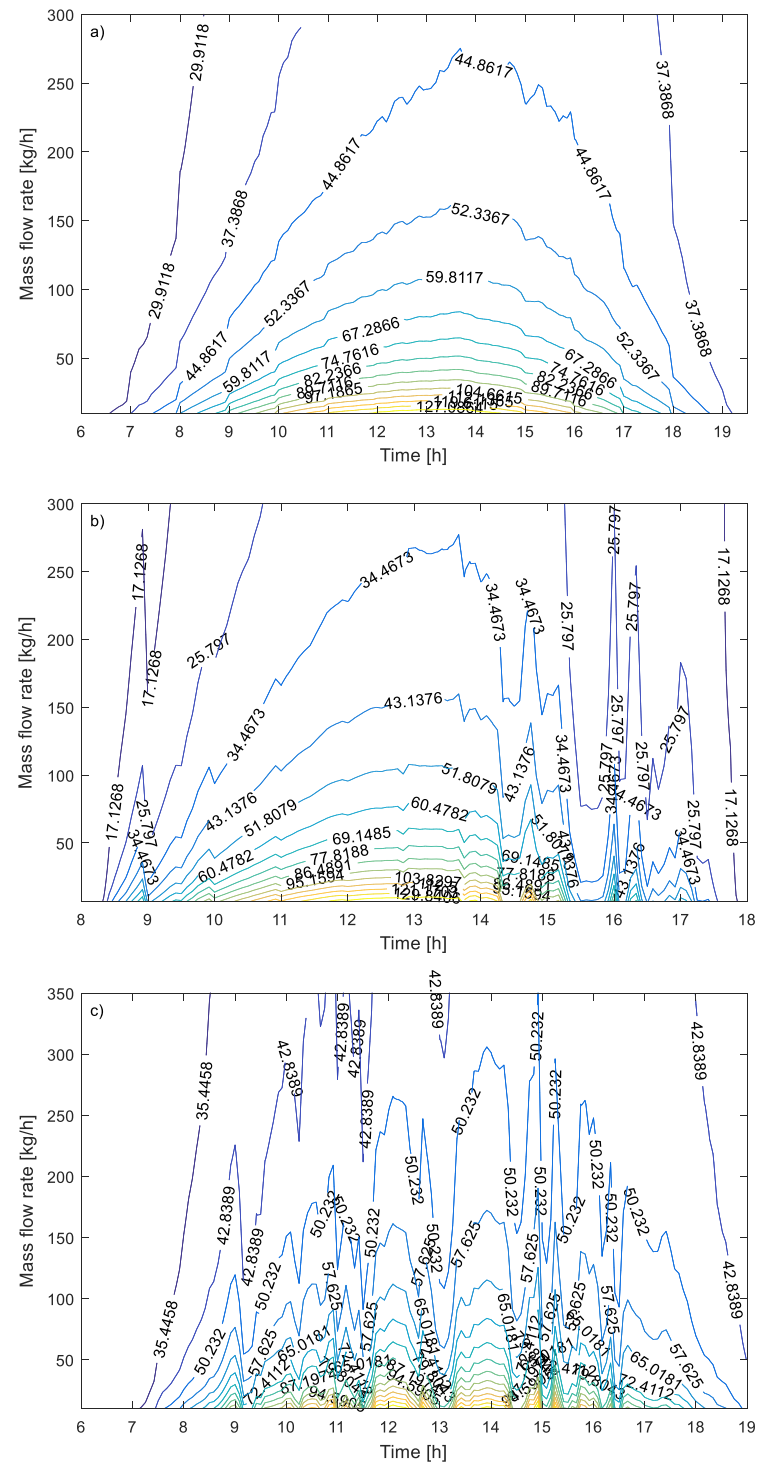

Figure 6. Observation of isotherm contours from 6h: 00 to 19h: 00: On : a) 06/11/2008 (Clear Sky), b) 01/14/2008

(Partly Cloudy sky) and c) 07/15/2008(Cloudy sky)

These results allow optimization of solar air collector proper functioning during well illuminated clear days by regulation of air flow rate in order to maintain drying optimum

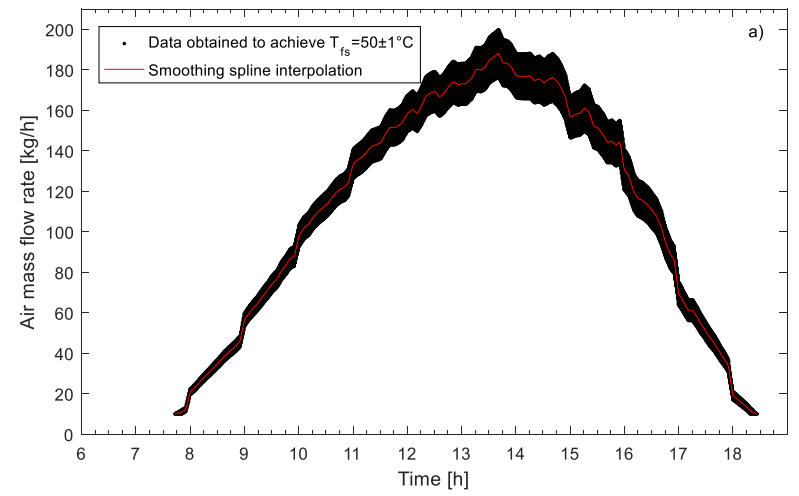

temperature over the whole day even under unwanted fluctuation of meteorological conditions.

In the case of Ghardaïa characterized by a semi-arid climate it was found that to maintain the functioning temperature optimum during all well illuminated days, a variations in air flow rate is required. In fact, this variation is estimated through simulation work carried out using data of very clear sky day, partly cloudy and cloudy sky day described by passage of clouds.

Figures 7, 8 and 9 show the variations in air flow rate as a function of climatic challenges curves. We used Matlab's spline toolbox to estimate all the smoothing splines. Based on the input data obtained by simulation, the algorithm computes the optimal smoothing parameter $P$ such that the penalized residual sum of squares is less than a tolerance value $\epsilon>0$. In all cases, we used the default value of $\mathrm{k}=2$ and $\epsilon=0.0001$. A statistical analyses applied to the proposed functions to simulate the daily values of air flow rate necessary to achieve the desired temperature are shown in Table 1. In general, all functions showed a good fit to the data.

The daily values of air flow rate necessary to achieve an optimum temperature are fitted by an adequate number of piecewise cubical polynomials that approximate smoothly the data points. In fact, the splines are piecewise-polynomial functions that blend smoothly and can be efficiently stored (as coefficient arrays) and manipulated on computers. The results could also be beneficial to system control designer. They can be used as basis for open loop control of solar collector in which the outlet temperature is maintained constant regardless to the fluctuation of meteorological conditions.

As can be seen from Figure 7a) in which the flow rate is plotted against time, the flow rate increases with time until a maximum value which correspond to the highest value of irradiance and then decrease as the irradiance value decreases. This is typical scenario of clear sky conditions. In case of partly cloudy sky it can be seen from the Figure 8a) a clear fluctuation in flow rate this correspond to low irradiance values resulting from occasional passage of clouds. The fluctuations in flow rate are more pronounced in case of cloudy day as shown in Figure 9a). This is common scenario of typical cloudy day in which the clouds passage frequency is high.

It can be inferred from Figure $7 \mathrm{~b}$ ) in which the flow rate versus time variation is plotted for both $50 \pm 1$ and $65 \pm 1{ }^{\circ} \mathrm{C}$ that the maximum flow rate is equal to $188.1 \mathrm{~kg} / \mathrm{h}$ in the first case i.e. $50 \pm 1{ }^{\circ} \mathrm{C}$ whilst in case of $65 \pm 1{ }^{\circ} \mathrm{C}$ the maximum is $90.92 \mathrm{~kg} / \mathrm{h}$.

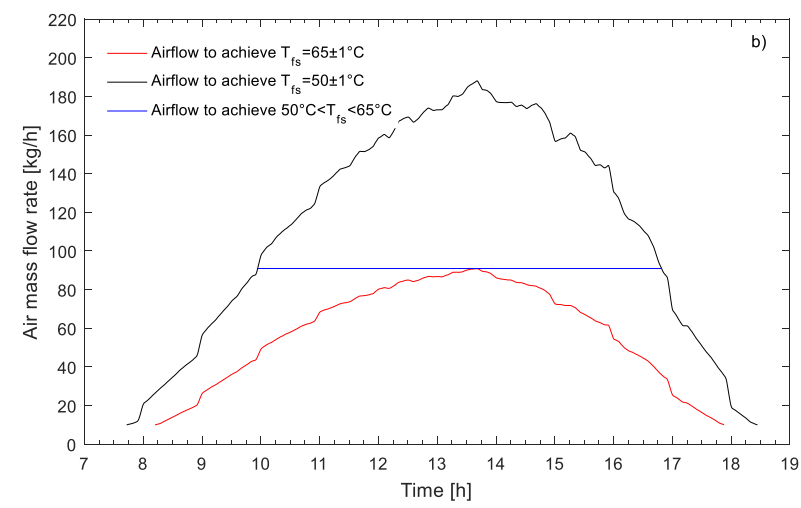

Figure 7. Variation of air flow rate necessary to achieve the desired temperature: on 06/11/2008, Clear Sky 

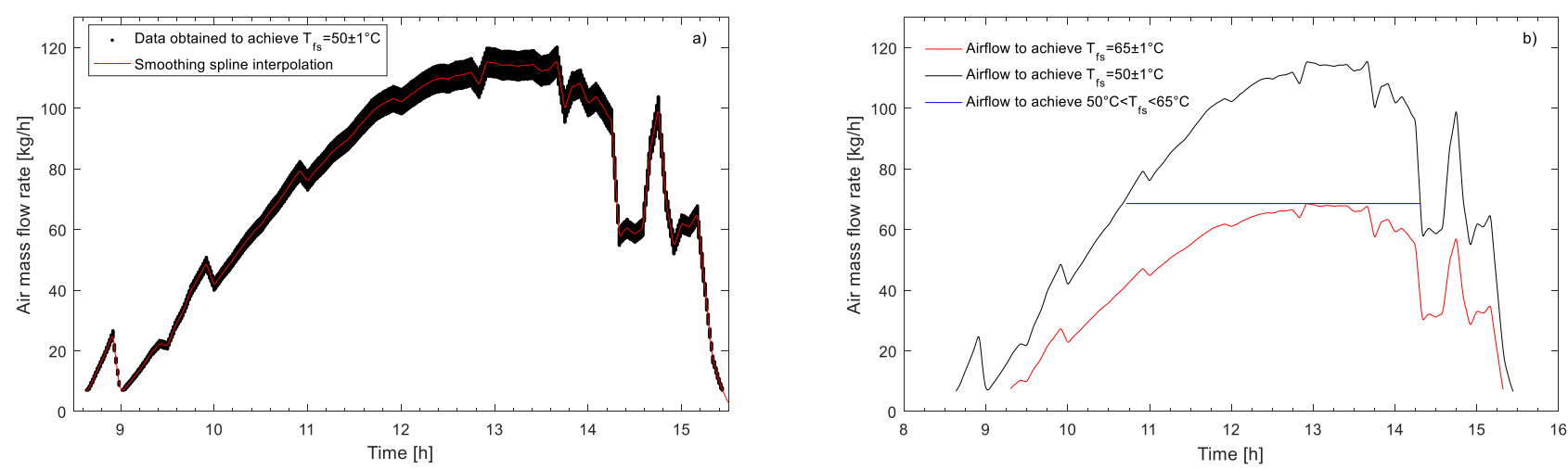

Figure 8. Variation of air flow rate necessary to achieve the desired temperature: on 01/14/2008, Partly Cloudy sky
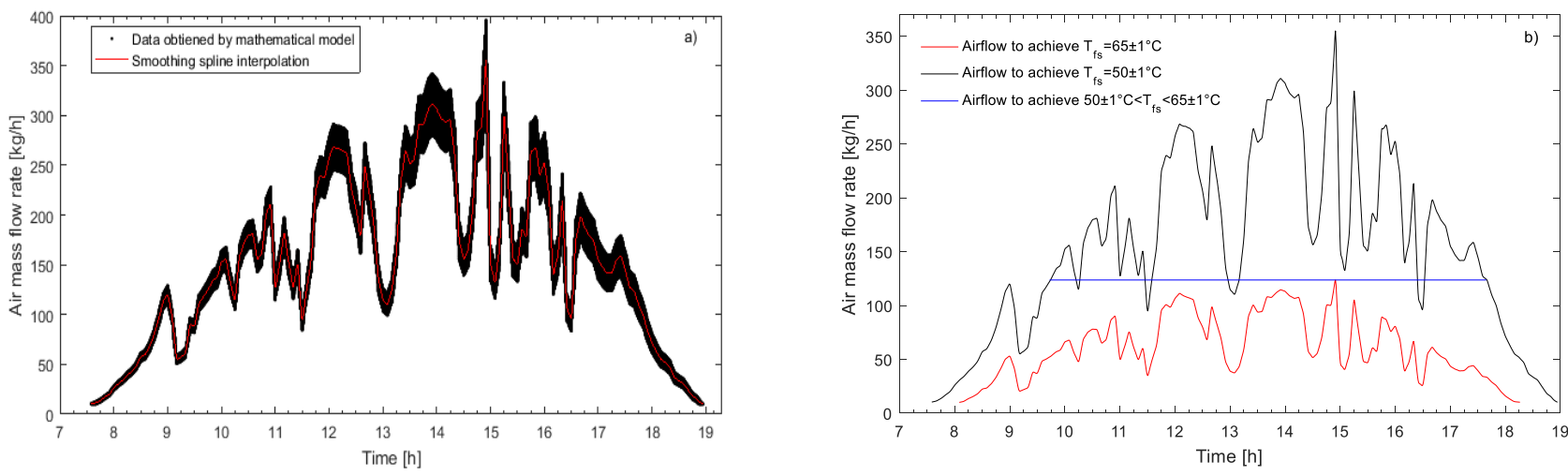

Figure 9. Variation of air flow rate necessary to achieve the desired temperature: On 07/15/2008, Cloudy Sky

For solar drying application at temperature situated between $50 \pm 1$ and $65 \pm 1^{\circ} \mathrm{C}$ the flow rate should have value between 188.1 and $90.92 \mathrm{~kg} / \mathrm{h}$. In the Figure $7 \mathrm{~b}$ ) it is also plotted the constant flow rate which allows high drying time without undermining the products quality. Drying with variable flow rate at temperature equal to $50 \pm 1{ }^{\circ} \mathrm{C}$ we can carry on the drying process from $07 \mathrm{~h}: 43$ to $18 \mathrm{~h}: 27$ i.e. 10 hours and 44 minutes with an aspiration of $1207.8 \mathrm{~kg}$ of air. By contrast, drying with constant flow the drying time is reduced to 6 hours and 53 minutes with aspiration of $625.5 \mathrm{~kg}$ of air. Thus variable flow rate allows a gain ratio in the aspired air amount of $93 \%$.

Table 1. Statistical tests of the smoothing spline used to fit the air mass flow rate curves to achieve the desired temperature for different sky types

\begin{tabular}{ccccccc}
\hline \multirow{3}{*}{ Statistical tests } & \multicolumn{9}{c}{ Desired temperature $\left[{ }^{\circ} \mathrm{C}\right]$} \\
\cline { 2 - 7 } & \multicolumn{2}{c}{ Clear sky $06 / 11 / 2008$} & \multicolumn{2}{c}{ Partly Cloudy sky 01/14/2008 } & \multicolumn{2}{c}{ Cloudy sky 07/15/2008 } \\
\cline { 2 - 7 } & $T_{f s}=50 \pm 1$ & $T_{f s}=65 \pm 1$ & $T_{f s}=50 \pm 1$ & $T_{f s}=65 \pm 1$ & $T_{f s}=50 \pm 1$ & $T_{f s}=65 \pm 1$ \\
\hline$R^{2}$ & 0.9856 & 0.9945 & 0.9943 & 0.9957 & 0.972 & 0.9937 \\
\hline$R M S E$ & 5.327 & 1.617 & 2.164 & 1.000 & 12.3029 & 2.202 \\
\hline$S S E$ & $1.306 \mathrm{e}+06$ & $3.507 \mathrm{e}+04$ & $5.851 \mathrm{e}+04$ & 5160 & $1.554 \mathrm{e}+07$ & $8.922 \mathrm{e}+04$ \\
\hline
\end{tabular}

It can be inferred from Figure $8 b$ ) in which the flow rate versus time variation is plotted for both $50 \pm 1$ and $65 \pm 1{ }^{\circ} \mathrm{C}$ that the maximum flow rate is equal to $115.3 \mathrm{~kg} / \mathrm{h}$ in the first case i.e. $50 \pm 1{ }^{\circ} \mathrm{C}$ whilst in case of $65 \pm 1{ }^{\circ} \mathrm{C}$ the maximum is $68.58 \mathrm{~kg} / \mathrm{h}$. For solar drying application at temperature situated between $50 \pm 1$ and $65 \pm 1{ }^{\circ} \mathrm{C}$ the flow rate should have value between 115.3 and $68.58 \mathrm{~kg} / \mathrm{h}$. In the Figure $8 \mathrm{~b}$ ) it is also plotted the flow rate which allows high drying time without undermining the products quality. Drying with variable flow rate at temperature equal to $50 \pm 1{ }^{\circ} \mathrm{C}$ we can carry on the drying process from $08 \mathrm{~h}: 38$ to $15 \mathrm{~h}: 26$ i.e. 6 hours and 49 minutes with an aspiration of $502.3 \mathrm{~kg}$ of air. By contrast, drying with constant flow the drying time is reduced to 3 hours and 35 minutes with aspiration of $246.2 \mathrm{~kg}$ of air. Thus variable flow rate allows a gain ratio in the air aspired amount of $104 \%$.
It can be inferred from Figure 9b) in which the flow rate versus time variation is plotted for both $50 \pm 1$ and $65 \pm 1{ }^{\circ} \mathrm{C}$ that the maximum flow rate is equal to $355.1 \mathrm{~kg} / \mathrm{h}$ in the first case i.e. $50 \pm 1{ }^{\circ} \mathrm{C}$ whilst in case of $65 \pm 1{ }^{\circ} \mathrm{C}$ the maximum is $123.7 \mathrm{~kg} / \mathrm{h}$. For solar drying application at temperature situated between $50 \pm 1$ and $65 \pm 1{ }^{\circ} \mathrm{C}$ the flow rate should have value between 350 and $120 \mathrm{~kg} / \mathrm{h}$. In the Figure $9 \mathrm{~b}$ ) it is also plotted the flow rate which allows high drying time without undermining the products quality. Drying with variable flow rate at temperature equal to $50 \pm 1{ }^{\circ} \mathrm{C}$ we can carry on the drying process from $07 \mathrm{~h}: 35$ to $18 \mathrm{~h}$ : 56 i.e. 11 hours and 22 minutes with an aspiration of $1748.2 \mathrm{~kg}$ of air. By contrast, drying with constant flow the drying time is reduced to 7 hours and 56 minutes with aspiration of 981.03 $\mathrm{kg}$ of air. Thus variable flow rate allows a gain ratio in the air aspired amount of $78 \%$. 
Indeed, the elaborated code allows optimizing the operation of solar air collector under varying meteorological weather conditions over the entire year. The flow rate variation doesn't need to be fast following a sudden fluctuation in meteorological conditions as the outlet temperature doesn't follow this fluctuation with comparable rate. As the collector outlet temperature corresponds to the cabinet temperature. It can be deduced that the latter one is regulated by controlling the former one. In This investigation the cabinet thermal behavior hasn't been dealt with.

\section{CONCLUSIONS}

The operations of solar drying process at high irradiance values engender an increase of the drying temperature, which undermine the dried product quality including nutritive value. To overcome this drawback, a function relating flow rate to drying optimal temperature and irradiance variation is devised. This is achieved by carrying out a simulation work by varying the flow rate in function of time and recording the corresponding temperatures under site common solar irradiance scenarios. Then, the plot of isotherm contours in function of time and flow rate is realized. From this plot the desired function of flow rate variation with time to have a constant outlet temperature is deduced. The simulation work was carried out under meteorological and solar resource that mimic those of the site where the drying process is to be done. To be more clear, the developed code used for calculation related to study of produced heat source by flat air solar air collector equipped with fins has enabled the investigation of instantaneous thermal behavior of the solar air collector and influence of the aero-thermal conditions on temperatures of the drying process at the solar air collector outlet in detail.

The fact that these parameters depend on undetermined variables in turn, the use of iterative methods was implemented. The incident irradiance on the solar air collector was subject to several fluctuations due to passage of occasional clouds and sudden change in ambient temperature and the peak output temperature depends on air flow rate. The global outcome of the simulation was satisfactory as the instantaneous air flow rate is put under control to maintain the drying temperature constant over the drying period. In doing so, the quality and nutritive value of the dried products are kept at an acceptable standard level.

It has been found also that drying with variable flow rate at optimum temperature equal to $50 \pm 1{ }^{\circ} \mathrm{C}$ the amount of air that was aspired at the inlet was $1207.8 \mathrm{~kg}$. By contrast, drying with constant flow rate a total $625.5 \mathrm{~kg}$ of air was aspired and it may result in fluctuation in drying temperature which affects the dried product quality. Thus variable flow rate allows a gain ratio in the aspired air amount of $93 \%$ and better product quality. This is valid for clear sky day. In case of partly and cloudy day, flow rate gain ratio were $104 \%$ and $78 \%$ respectively.

The results could also be beneficial to system control designer. They can be used as basis for open loop control of solar collector in which the outlet temperature is maintained constant regardless to the fluctuation of meteorological conditions.

All in all, the obtained results could be beneficial to solar drying systems practitioners in arid and semi-arid region to have a better quality product in challenging meteorological conditions.

\section{REFERENCES}

[1] Karim MA, Hawlader MNA. (2006). Performance evaluation of a v-groove solar air collector for drying applications. Applied Thermal Engineering 26(1): 121. http://dx.doi.org/10.1016/j.applthermaleng.2005.03.017

[2] Varalakshmi K. (2016). Role of conventional energy in rural development in India: feasibility analysis of solar drying technology. International Journal of Energy and Environmental Engineering 7(3): 321. http://dx.doi.org/10.1007/s40095-016-0210-8

[3] El-Sawi AM, Wifi AS, Younan MY, Elsayed EA, Basily BB. (2010). Application of folded sheet metal in flat bed solar air collectors. Applied Thermal Engineering 30(89):

864. http://dx.doi.org/10.1016/j.applthermaleng.2009.12.018

[4] Yeh HM, Lin TT. (1996). Efficiency improvement of flat-plate solar air heaters. Energy 21(6): 435. http://dx.doi.org/10.1016/0360-5442(96)00008-4

[5] Choudhury C. (1988). A solar air heater for low temperature applications. Sol Energy 40(4): 335. http://dx.doi.org/10.1016/0038-092X(88)90006-0

[6] Hollands KGT. (1963). Directional selectivity, emittance, and absorptance properties of vee corrugated specular surfaces. Solar Energy 7(3): 108. http://dx.doi.org/10.1016/0038-092X(63)90036-7

[7] Gao W, Lin W, Liu T, Xia C. (2007). Analytical and experimental studies on the thermal performance of cross-corrugated and flat-plate solar air heaters. Applied $\begin{array}{lll}\text { Energy } & 84(4) \text { : } & \end{array}$ http://dx.doi.org/10.1016/j.apenergy.2006.02.005

[8] Alvarez G, Arce J, Lira L, Heras MR. (2004). Thermal performance of an air solar collector with an absorber plate made of recyclable aluminum cans. Solar Energy $77(1)$ :

107. http://dx.doi.org/10.1016/j.solener.2004.02.007

[9] Moummi N, Youcef-Ali S, Moummi A, Desmons JY. (2004). Energy analysis of a solar air collector with rows of fins. Renewable Energy 29(13): 2053. http://dx.doi.org/10.1016/j.renene.2003.11.006

[10] Patil AK, Saini JS, Kumar K. (2012). Heat transfer and friction characteristics of solar air heater duct roughened by broken $\mathrm{V}$-shape ribs combined with staggered rib piece. Journal of Renewable and Sustainable Energy 4(1): 013115. http://dx.doi.org/10.1063/1.3682072

[11] Sharma A, Varun, Kumar P, Bharadwaj G. (2013). Heat transfer and friction characteristics of double pass solar air heater having $\mathrm{V}$-shaped roughness on the absorber plate. Journal of Renewable and Sustainable Energy 5(2): 023109. http://dx.doi.org/10.1063/1.4794747

[12] Ravi RK, Saini RP. (2016). Experimental investigation on performance of a double pass artificial roughened solar air heater duct having roughness elements of the combination of discrete multi $\mathrm{V}$ shaped and staggered ribs. $\quad$ Energy $116: \quad 507$. http://dx.doi.org/10.1016/j.energy.2016.09.138

[13] Lanjewar AM, Bhagoria JL, Agrawal MK. (2015). Review of development of artificial roughness in solar air heater and performance evaluation of different orientations for double arc rib roughness. Renewable and Sustainable Energy Reviews 43: 1214. http://dx.doi.org/10.1016/j.rser.2014.11.081

[14] Nayak RK, Singh SN. (2016). Effect of geometrical aspects on the performance of jet plate solar air heater. 
Solar Energy

137:

434.

http://dx.doi.org/10.1016/j.solener.2016.08.024

[15] Goel AK, Singh SN. (2017). Thermal performance of solar air heater using jet impingement technique with longitudinal fins. Journal of Scientific and Industrial Research 76(12): 780. http://nopr.niscair.res.in/handle/123456789/43196

[16] Abene A, Dubois V, Le Ray M, Ouagued A. (2004). Study of a solar air flat plate collector: use of obstacles and application for the drying of grape. Journal of Food Engineering 65(1): http://dx.doi.org/10.1016/j.jfoodeng.2003.11.002

[17] Singh SN. (2006). Performance studies on continuous longitudinal fins solar air heater. Journal of ISM Dhanbad 2: 39.

[18] Goel AK, Singh SN. (2017). Performance studies of a jet plate solar air heater with longitudinal fins. International Journal of Ambient Energy https://doi.org/10.1080/01430750.2017.1372808

[19] Giovanni T. (2011). Performance of solar air heater ducts with different types of ribs on the absorber plate. Energy 36(11):

6651. http://dx.doi.org/10.1016/j.energy.2011.08.043

[20] Arunachalam UP, Edwin M. (2017). Experimental investigations on thermal performance of solar air heater with different absorber plates. International Journal of

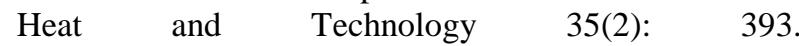
http://dx.doi.org/10.18280/ijht.350223

[21] Saha SN, Sharma SP. (2017). Performance evaluation of corrugated absorber double flow solar air heater based on energy, effective and exergy efficiencies. International Journal of Mechanical \& Mechatronics Engineering 17(1): 63

[22] Kundu B. (2008). Performance and optimum design analysis of an absorber plate fin using recto-trapezoidal $\begin{array}{llll}\text { profile. } & \text { Solar } & \text { Energy }\end{array}$ http://dx.doi.org/10.1016/j.solener.2007.05.002

[23] Lim YY, Lim TT, Tee JJ. (2007). Antioxidant properties of several tropical fruits: A comparative study. Food Chemistry 103(3): http://dx.doi.org/10.1016/j.foodchem.2006.08.038

[24] Omolola AO, Jideani AI, Kapila PF. (2017). Quality properties of fruits as affected by drying operation. Critical Reviews in Food Science and Nutrition 57(1): 95. http://dx.doi.org/10.1080/10408398.2013.859563

[25] Oliveira MS, Ramos IN, Brandão TRS, Silva CLM. (2015). Effect of air-drying temperature on the quality and bioactive characteristics of dried galega kale (brassica oleracea 1. var. acephala). Journal of Food Processing and Preservation 39(6): 2485. http://dx.doi.org/10.1111/jfpp.12498

[26] Vega-Galvez A., Scala KD, Rodriguez K, LemusMondaca R, Miranda M, Lopez J, Perez-Won M. (2009). Effect of air-drying temperature on physico-chemical properties, antioxidant capacity, colour and total phenolic content of red pepper (Capsicum annuum, L. var. Hungarian). Food Chemistry 117(4): 647. http://dx.doi.org/10.1016/j.foodchem.2009.04.066

[27] Pendre NK, Nema PK, Sharma HP, Rathore SS, Kushwah SS. (2012). Effect of drying temperature and slice size on quality of dried okra (Abelmoschus esculentus (L.) Moench). Journal of Food Science and Technology 49(3): 378. http://dx.doi.org/10.1007/s13197-011-0427-8
[28] Icier F. (2010). Ohmic blanching effects on drying of vegetable byproduct. Journal of Food Process Engineering 33(4): 661. https://doi.org/10.1111/j.17454530.2008.00295.x

[29] Korus A. (2011). Effect of preliminary processing, method of drying and storage temperature on the level of antioxidants in kale (Brassica oleracea L. var. acephala) leaves 44(8):

1711. http://dx.doi.org/10.1016/j.lwt.2011.03.014

[30] Kaya A, Aydına O, Kolaylı S. (2010). Effect of different drying conditions on the vitamin $\mathrm{C}$ (ascorbic acid) content of Hayward kiwifruits (Actinidia deliciosa Planch). Food and Bioproducts Processing 88(2-3): 165. http://dx.doi.org/10.1016/j.fbp.2008.12.001

[31] Youcef-Ali S, Desmons JY. (2007). Influence of the aerothermic parameters and the product quantity on the production capacity of an indirect solar dryer. Renewable $\begin{array}{lll}\text { Energy } 32(3): & 496 .\end{array}$ http://dx.doi.org/10.1016/j.renene.2006.05.004

[32] Fudholi A, Sopian K, Ruslan MH, Othman MY. (2013). Performance and cost benefits analysis of double-pass solar collector with and without fins. Energy Conversion and Management 76: 8 . http://dx.doi.org/10.1016/j.enconman.2013.07.015

[33] Sopian K, Alghoul MA, Alfegi EM, Sulaiman MY, Mus EA. (2009). Evaluation of thermal efficiency of doublepass solar collector with porous-nonporous media. $\begin{array}{lll}\text { Renewable } \quad \text { Energy } & 34(3) \text { : } & 640 .\end{array}$ https://doi.org/10.1016/j.renene.2008.05.027

[34] Agbossou K, Tetang FA, Boroze TE, N'wuitcha K, Napo K, Zeghmati B. (2016). Theoretical and experimental study of thermal performance of flat plate air heating collector. International Journal of Science and Technology 5(10): 473.

[35] Sopian K, Yigit KS, Liu HT, Kaka S, Veziroglu TN. (1996). Performance analysis of photovoltaic thermal air heaters. Energy Conversion and Management 37(11): 1657. http://dx.doi.org/10.1016/0196-8904(96)00010-6

[36] El Khadraoui A, Bouadila S, Kooli S, Guizani A, Farhat A. (2016). Solar air heater with phase change material: An energy analysis and a comparative study. Applied Thermal Engineering 107: 1057. http://dx.doi.org/10.1016/j.applthermaleng.2016.07.004

[37] Harrouni S. (2008). Fractal classification of typical meteorological days from global solar irradiance: application to five sites of different climates. In: Badescu V (ed) Modelling solar radiation at the Earth surface. Springer, Berlin. pp. 29-54.

[38] Padovan A, Col DD. (2010). Measurement and modeling of solar irradiance components on horizontal and tilted planes. Solar Energy 84(12): 2068. http://dx.doi.org/10.1016/j.solener.2010.09.009

[39] Daguenet M. (1985). Les Séchoirs Solaires: Théorie et Pratique, edition de l'UNESCO. Paris.

[40] McAdams, William H. (William Henry). (1954). Heat transmission, third ed., McGraw Hill, New York. https://trove.nla.gov.au/version/12307044

[41] Duffie JA, Beckman WA. (1980). Solar Engineering of Thermal Processes. 0th edition., John Wiley and Sons, New York, pp. 398-402.

[42] Yeh HM, (1992). Theory of baffled solar air heaters. Energy 17(7): 697. http://dx.doi.org/10.1016/03605442(92)90077-D 
[43] Ramesh KS, Dusan PS. (2003). Fundamentals of heat exchanger design, first ed., John Wiley \& Sons, New Jersey, Canada.

[44] Sparrow EM, Ramsey JW, Mass EA. (1979). Effect of Finite Width on Heat Transfer and Fluid Flow about an Inclined Rectangular Plate. Journal of Heat Transfer 101(2): 199. http://dx.doi.org/10.1115/1.3450946

[45] Buchberg H, Catton I, Edwards DK. (1976). Natural convection in enclosed spaces - a review of application to solar energy collection. Journal of Heat Transfer 98(2): 182. http://dx.doi.org/10.1115/1.3450516

[46] Gnielinski V. (1976). New equations for heat and mass transfer in turbulent pipe and channel flow. International Chemical Engineering 16(2): 359.

[47] Swinbank WC. (1963). Long-wave radiation from clear skies. Quarterly Journal of the Royal Meteorological Society 89(381):

339. http://dx.doi.org/10.1002/qj.49708938105

[48] Lienhard IV JH, Lienhard V JH. (2006). A Heat Transfer Textbook, third ed., Phlogiston Press, Cambridge, Massachusetts.

[49] Manglik RM, Bergles AE. (1995). Heat transfer and pressure drop correlations for the rectangular offset strip fin compact heat exchanger. Experimental Thermal and $\begin{array}{lll}\text { Fluid } & \text { Science } & 10(2):\end{array}$ http://dx.doi.org/10.1016/0894-1777(94)00096-Q

[50] Hu S, Herold KE. (1995). Prandtl number effect on offset fin heat exchanger performance: experimental results. International Journal of Heat and Mass Transfer 38(6): 1053. http://dx.doi.org/10.1016/0017-9310(94)00220-P

[51] Aoues K, Moummi N, Zellouf M, Benchabane A. (2011). Thermal performance improvement of solar air flat plate collector: a theoretical analysis and an experimental study in Biskra, Algeria. International Journal of $\begin{array}{lll}\text { Ambient } & \text { Energy } & 32(2):\end{array}$ http://dx.doi.org/10.1080/01430750.2011.584469

[52] De Boor C. (1978). A Practical Guide to Splines, in Applied Mathematical Sciences, in: John F et al, ed., Springer-Verlag, New York.

[53] Fox J (2000). Nonparametric Simple Regression: Scatterplot Smoothing, ed., Sage Publications, Thousand Oaks, London, New Delhi.

[54] Shahraray B, Anderson DJ. (1989). Optimal estimation of contour properties by cross-validated regularization. IEEE Transactions on Pattern Analysis and Machine Intelligence $11(6)$ : 600 . http://dx.doi.org/10.1109/34.24794

[55] Benseddik A, Azzi A, Zidoune MN, Khanniche R, Besombes C. Empirical and diffusion models of rehydration process of differently dried pumpkin slices. Journal of the Saudi Society of Agricultural Sciences Xxx (2018). https://doi.org/10.1016/j.jssas.2018.01.003

[56] (C) 1994-2018 The MathWorks, Inc., Evaluating Goodness of Fit, online available at: https://www.mathworks.com/help/curvefit/evaluatinggoodness-of-fit.html, 2017.

[57] Naz R. (2012). Physical properties, sensory attributes and consumer preference of fruit leather. Pakistan Journal of Food Sciences 22(4): 188.

[58] Gupta PM, Das AS, Barai RC, Pusadkar SC, Pawar VG. (2017). Design and construction of solar dryer for drying agricultural products. International Research Journal of Engineering and Technology 4(3): 1946.

[59] Papade CV, Boda MA. (2014). Design \& development of indirect type solar dryer with energy storing material. International Journal of Innovative Research in Advanced Engineering 1(12): 109.

[60] Abdullahi Y, Momoh M, Garba MM, Musa M. (2013). Design and construction of an adjustable and collapsible natural convection solar dryer. International Journal of Computational Engineering Research 3(6): 1.

\section{NOMENCLATURE}

$A_{d}$

$A_{c}$

$A_{f}$

C

$C_{p}$

$D$

$D_{H}$

$e_{i s}$

ET

$F^{\prime}$

G

$G_{I}$

$h$

$h_{f}$

$h_{r c}$

$h_{1}$

$h_{2}$

$h_{r}$

$h_{v v}$

$G_{I}$

l

$l_{c}$

$L_{c}$

$L C$

$L C T$

$m$

$\dot{m}$

$\dot{m}_{\text {opt }}$ cross sectional area in the airflow pass $\left[\mathrm{m}^{2}\right]$ surface area of the absorbing plate $\left[\mathrm{m}^{2}\right]$ fin surface area $\left[\mathrm{m}^{2}\right]$ legal time correction specific heat of air at constant pressure $\left[\mathrm{Jkg}^{-1} \mathrm{~K}^{-1}\right]$

height of air tunnel in solar air collector [m] hydraulic diameter $[\mathrm{m}]$ thickness of the insulating [m] equation of time [min] efficiency factor of solar air collector air mass flow rate $\left[\mathrm{kgh}^{-1}\right]$ global irradiance incident on solar air collector $\left[\mathrm{Wm}^{-2}\right]$

height of the offset strip fin channel in the solar air collector [m]

convection heat transfer coefficient between the fins and the air $\left[\mathrm{Wm}^{-1} \mathrm{~K}^{-1}\right]$

radiation heat transfer coefficient between the wall and the sky $\left[\mathrm{Wm}^{-1} \mathrm{~K}^{-1}\right]$

convection heat transfer coefficient between the absorber plate and air $\left[\mathrm{Wm}^{-1} \mathrm{~K}^{-1}\right.$ ]

convection heat transfer coefficient between the channel back and air $\left[\mathrm{Wm}^{-1} \mathrm{~K}^{-1}\right]$

radiant heat-transfer coefficient between two parallel plates $\left[\mathrm{Wm}^{-1} \mathrm{~K}^{-1}\right]$

convective heat transfer coefficient due to wind on the outer cover of the solar air collector $\left[\mathrm{Wm}^{-1} \mathrm{~K}^{-1}\right]$

global irradiance incident on solar air collector $\left[\mathrm{Wm}^{-2}\right]$

Colburn factor

length of the offset strip-fin [m]

solar air collector width [m]

solar air collector length [m]

longitude correction [h]

local clock time [h]

quantity defined by $\operatorname{Eq}(22)\left[\mathrm{m}^{-1}\right]$

air mass flow rate $\left[\mathrm{kgs}^{-1}\right]$

optimal air mass flow rate in a solar air collector $\left[\mathrm{kgs}^{-1}\right]$ 


\begin{tabular}{|c|c|}
\hline$\dot{m}_{\text {opt }}$ data & $\begin{array}{l}\text { data of air flow rate obtained by } \\
\text { calculation using models of solar air }\end{array}$ \\
\hline$\dot{m}_{o p t}{ }_{\text {pré }}$ & $\begin{array}{l}\text { collector }\left[\mathrm{kgs}^{-1}\right] \\
\text { predicted values of air flow rate } \\
\text { necessary to achieve an optimum } \\
\text { temperature obtained from the model } \\
{\left[\mathrm{kgs}^{-1}\right]}\end{array}$ \\
\hline$N$ & $\begin{array}{l}\text { number of data obtained by calculation } \\
\text { using models of solar air collector }\end{array}$ \\
\hline$n$ & number of polynomial constants \\
\hline$N u$ & Nusselt number \\
\hline$P_{u}$ & $\begin{array}{l}\text { useful power gain provided by the solar } \\
\text { air collector [W] }\end{array}$ \\
\hline $\operatorname{Pr}$ & Prandtl number \\
\hline Re & Reynolds number \\
\hline$S t$ & Stanton number \\
\hline$s$ & spacing of the offset strip-fin [m] \\
\hline$t$ & thickness of the offset strip-fin [m] \\
\hline$T S$ & solar time $[h]$ \\
\hline$T_{a}$ & ambient temperature $\left[{ }^{\circ} \mathrm{C}\right]$ \\
\hline$T_{f}$ & $\begin{array}{l}\text { air stream temperature of step in the } \\
\text { solar air collector }\left[{ }^{\circ} \mathrm{C}\right]\end{array}$ \\
\hline$T_{f e}$ & $\begin{array}{l}\text { inlet air temperature of step in the solar } \\
\text { air collector }\left[{ }^{\circ} \mathrm{C}\right]\end{array}$ \\
\hline$T_{f s}$ & $\begin{array}{l}\text { outlet fluid temperature of step in the } \\
\text { solar air collector }\left[{ }^{\circ} \mathrm{C}\right]\end{array}$ \\
\hline$U_{b}$ & $\begin{array}{l}\text { loss coefficient from the surfaces of } \\
\text { edges and the bottom of the solar air } \\
\text { collector to the ambient }\left[\mathrm{Wm} \mathrm{m}^{-2} \mathrm{~K}^{-1}\right]\end{array}$ \\
\hline
\end{tabular}

$U_{t} \quad$ loss coefficient from the top of the solar air collector to the ambient $\left[\mathrm{Wm}^{-2} \mathrm{~K}^{-1}\right]$

$U_{L} \quad$ overall loss coefficient $\left[\mathrm{Wm}^{-2} \mathrm{~K}^{-1}\right]$

$V_{f} \quad$ air velocity in the tunnel $\left[\mathrm{ms}^{-1}\right]$

$V_{w} \quad$ wind velocity $\left[\mathrm{ms}^{-1}\right]$

\section{Greek symbols}

$\begin{array}{ll}\alpha, \delta, \gamma & \text { fin geometric parameters } \\ \beta & \text { solar air collector tilt (degrees) } \\ \varepsilon_{\mathrm{b}} & \text { wood emissivity } \\ \varepsilon_{\mathrm{v}} & \text { emittance of glass } \\ \varepsilon_{\mathrm{n}} & \text { emittance of black plate } \\ \varepsilon_{1} & \text { emissivity of the inner wall of the } \\ & \text { absorber plate } \\ \varepsilon_{2} & \text { emissivity of the back plate wall } \\ \lambda_{\mathrm{f}} & \text { thermal conductivity of air } \\ & {\left[W m^{-1} K^{-1}\right]} \\ \lambda_{\text {is }} & \text { thermal conductivity of insulating } \\ \mathrm{k}_{\mathrm{f}} & {\left[W m^{-1} K^{-1}\right]} \\ v_{\mathrm{f}} & \left.\text { fin metal conductivity [Wm }{ }^{-1} \mathrm{~K}^{-1}\right] \\ \rho_{\mathrm{f}} & \text { kinematic viscosity } m^{2} s^{-1} \\ \eta_{\mathrm{f}} & \left.\text { air density [kgm }{ }^{-3}\right] \\ \eta_{\mathrm{s}} & \text { efficiency of a single fin } \\ \sigma & \text { overall surface efficiency } \\ \tau_{v} & \text { the Stefan Boltzmann constant } \\ \alpha_{n} & \text { transmittance of glass cover } \\ & \text { absorptivity of the absorbing plate }\end{array}$

